\title{
Teoria e prática tutorial em educação a distância
}

\section{Distance education's tutoring practice and theory}

\author{
Onilza Borges Martins*
}

\begin{abstract}
RESUMO
A educação a distância parte da exigência de uma nova concepção de ensino, e de docentes, até então desvelada sobre o manto da didática no espaço presencial da sala de aula. Novas posturas pedagógicas e metodológicas são exigidas para responder ao atual conjunto de conhecimentos exigidos pelas transformações do mundo contemporâneo. A EAD exige uma interlocução continuada mediante o diálogo efetivo entre alunos, docentes e tutores ou orientadores acadêmicos e traz consigo a possibilidade da adoção de um novo tempo escolar, com um maior respeito aos ritmos pessoais de cada estudante. Como mediador neste processo, o professor tutor assume papel relevante, atuando como intérprete do curso junto ao aluno, esclarecendo suas dúvidas, estimulando-o a prosseguir e ao mesmo tempo participando do processo de avaliação da aprendizagem.

Palavras-chave: educação a distância, tutoria, orientação acadêmica, formação de tutores/orientadores em educação a distância.
\end{abstract}

\begin{abstract}
Distance learning requires a new conception towards education, teaching and students, up to now veiled under the didactical relationships built within the existing espace and presence on classroom. New pedagogical

* Doutora em Educação. Pós-Doutorado em Educação Superior a Distância. Professora dos Cursos de Pós-Graduação do Setor de Ciências Sociais Aplicadas (UFPR) e Consultora do NEAD - UFPR. E-mail: onilza@ nead.ufpr.br
\end{abstract}


and metodological standpoints are posed to answer the kind of knowledge required by contemporary transformations on society. Distance Education demands an continuing exchange between students, teachers and tutors and opens possibilities for the adoption of a new timing for learning, based on the students' individual pace. As a mediator of this process the tutor have an important role helping the students in advancing their learning processes.

Key-words: distance education, tutoring, tutorage and orientation, tutor's training for distance education.

\section{À guisa de introdução: um mapa reflexivo da cultura docente e discente em EAD}

O uso de tecnologias, cada vez mais presente na vida das pessoas, identifica-se como um dos elementos do conjunto que caracteriza a modernidade.

A revolução da microeletrônica e da tecnologia digital vem provocando, nos últimos dez anos, profundas e aceleradas transformações na sociedade. Rompe-se com o velho paradigma da sociedade industrial e fordista do início do século e instaura-se o paradigma da sociedade da informação e do conhecimento.

Tal sociedade baseia-se, fundamentalmente, no aumento da produtividade, na modernização dos métodos de gestão, nas novas tecnologias, particularmente as da informação e da comunicação que rompem as barreiras de tempo e espaço, na alta velocidade das decisões e no aumento da capacidade criativa do homem.

Esta é a "sociedade do saber", na qual o conhecimento torna-se um recurso social com funções comparáveis às do trabalho no processo de produção, saber este que pode ser convertido em "capital intelectual".

O desenvolvimento da informática e a difusão da internet estão ampliando o universo de usuários, principalmente quando a atividade ou a profissão colocam o indivíduo em contato permanente com o computador e suas ferramentas.

As profissões, por conseqüência, vêm se apropriando cada vez mais das novas tecnologias, que marcam a sociedade da informação ou do saber. Estamos atravessando um momento singular e ao mesmo tempo rico em questionamentos porque vem engendrando uma nova ordem, ao valorizar a 
formação de pessoas qualificadas para gerar, transformar e aplicar novas tecnologias e universalizar a informação. Por sua vez, emergem as ofertas de novas modalidades de formação profissional, a diversificação das modalidades de ensino e de modelos institucionais de gestão, fazendo da educação continuada a regra, e não mais a exceção.

Os desafios impostos nesta nova ordem que promete aventura, aplicamse, sobretudo, às rotinas do trabalho e da vida em suas atividades econômicas, social e cultural. Trata-se de um desafio que exige deixar um método de domínio para aprender o novo: uma aprendizagem quase compulsória em algumas situações do cotidiano que colocam o indivíduo em contato com códigos de barras, mensagens, operações e planilhas eletrônicas que compõem uma série de novos tipos de atividades exigentes de um novo saber.

O sentimento de obsolescência da prática profissional e das idéias ataca todas as pessoas que se encontram engrenadas, inseridas de alguma forma neste contexto complexo.

A questão que se coloca para a universidade remete ao compromisso com a qualidade do ensino e a responsabilidade social que a prática pedagógica, por si só, não assume. No caso da formação técnica - na informática, por exemplo, área cuja velocidade de inovações não se compara a nenhuma outra, e que exige qualificação profissional e atualizações permanentes, encontramos uma situação diferenciada no que diz respeito ao trabalho pedagógico. O caráter técnico do conhecimento permite que um grande número de publicações de novos programas e ferramentas ofereçam possibilidades de auto-aprendizagem, o que leva muito comumente a processar-se a aprendizagem autônoma e a distância.

Por sua vez, a educação a distância mediada por computador revela-se, a cada dia, uma perspectiva de crescimento das práticas profissionais. Nos últimos cinco anos, a universidade tem trabalhado com essa questão, no sentido de buscar uma redefinição do conceito de ensino a distância (SOARES, 2000).

A opção da universidade por caminhar em direção à sociedade do conhecimento e da informação significa, por exemplo, ampliar o universo do desenvolvimento de práticas que correspondam ao ritmo, à velocidade e à exigência de perfil do profissional qualificado para operar renovação.

Ser qualificado, hoje, significa ser capaz de uma prática profissional equipada e atualizada - desafio que poucos conseguem assumir e vencer, tendo em vista a velocidade das mudanças e o descompasso no cotidiano do trabalho e das relações sociais.

As exigências por qualificação transitam entre os diversos níveis da profissionalização. Cobra-se a qualificação do desempregado, para que possa 
conseguir um emprego, assim como se cobra a qualificação do empregado para que possa ser mantido no posto, fato este que origina uma onda de qualificação profissional a partir da revolução tecnológica na sociedade e no trabalho.

Não obstante esse processo de ruptura e o surgimento de uma nova ordem socioeconômica que está demandando um outro perfil de formação profissional, as universidades responsáveis pela formação básica na graduação e na pós-graduação, em muitos dos casos, continuam formando profissionais como há 20 anos. A cada ano, cresce o contingente de profissionais desempregados, jovens e adultos que, talvez, nunca tenham oportunidade de trabalhar no seu campo profissional.

A tradição da didática e a da soberania da aula presencial imprimiram uma mística que identifica o professor como protagonista principal do ato de aprender e ensinar. Esta concepção, nutrida pela pedagogia tradicional, foi-se modificando historicamente, projetando, em nossos dias, uma polêmica sobre a formação de professores e seus descompassos com o desenvolvimento social.

As certezas de outrora, que os professores tentavam passar para os alunos, foram substituídas por incertezas e por questionamentos polêmicos que ficam sem respostas. Diante desses professores, se delineia a necessidade incansável de conhecer o novo, motor de um empreendedorismo rumo a um futuro que vai sendo construído e rapidamente superado.

O investimento tecnológico na educação faz parte da convicção de que a educação é um componente substancial de qualquer política de desenvolvimento, como bem em si e como instrumentalização da cidadania.

Cabe evidenciar, assim, que a educação a distância parte da exigência de uma nova concepção de ensino e de docentes, até então abrigada sob o manto da didática no espaço presencial da sala de aula. Novas posturas pedagógicas e metodológicas são exigidas para responder às transformações que colocam as relações sociais do mundo contemporâneo em discussão permanente, pela indagação sobre os conteúdos e sua validade no atual conjunto de conhecimentos exigidos. Como se vê, trata-se de uma questão de currículo e fins a que se destina o saber.

As indagações em torno das avaliações em torno desse processo de ensino e aprendizagem e da pesquisa nele fecundada despertam suspeitas e criam hipóteses acerca de qualidade, confiabilidade e, sobretudo, do futuro incerto que essas práticas projetam.

As resistências pedagógicas que circundam as práticas de educação a distância não têm impedido, contudo, que estudos e práticas se desenvolvam, 
apontando perspectivas que contemplam essas novas características do ensino inaugurando metodologias de interação (SOARES, 2000).

Percebe-se assim a metodologia como principal responsável pela instalação do novo, na medida em que propõe novas indagações sobre o conteúdo, obrigando a buscar novos pontos de vista acerca do objeto de estudo e do avanço do conhecimento.

Por sua vez, preparar a aula para ser veiculada pela rede exige um domínio na seleção dos conteúdos para a elaboração de um encontro virtual, que deve passar pelo crivo do essencial, ou seja, priorizar os temas significativos para a reflexão, a análise e a produção de conhecimentos novos. Esta seleção de conteúdos deve evitar as armadilhas da reprodução de cópias, de trechos de outros autores, ou da montagem de apostilas que nada mais fazem que ressuscitar posturas tradicionais já abolidas na aula presencial: os conteúdos devem ser selecionados, de forma questionadora e problemática.

Para dar conta desse compromisso, a universidade precisa ser constantemente lugar de produção científica, fato este que requer seja ela também um local de reflexão, já que o núcleo de qualidade da vida acadêmica se diferencia pela produção própria/coletiva e crítica, num contexto pluralista e democrático.

O sistema educacional tem nessa perspectiva um papel primordial. Você já refletiu sobre este aspecto?

Estas questões exigem uma mudança importante no papel e na formação do professor. Os softwares adequados são companheiros contínuos deste caminho. É preciso insistir na idéia de que as multimídias não transformam o trabalho docente, elas apenas expressam com grande impacto os novos cenários da sociedade contemporânea e permitem um armazenamento enorme de informações, por meio de entretenimentos veiculados por novas linguagens.

Para cumprir esses objetivos e funções, você considera que a atual estrutura do sistema educacional tem condições de responder às expectativas da sociedade? Registre na agenda pessoal suas reflexões.

A utilização das novas tecnologias como recurso didático traz à tona a necessidade de encontrar um novo conceito que não se assente numa dicotomia rígida entre os processos de educação presencial daqueles da hoje chamada educação a distância, pois as possibilidades cada vez mais intensas de conectividade e de interação, propiciadas pela internet e pelo desenvolvimento das telecomunicações em geral, tornam a noção de presença e distância bastante discutíveis.

Tanto as universidades públicas como as instituições privadas precisam urgentemente utilizar o espaço virtual como uma possibilidade real de traba- 
lho cooperativo a serviço da cultura, da ciência e da tecnologia, potencializando as competências nelas existentes, não apenas para cursos a distância, mas para modernizar e flexibilizar as disciplinas presenciais, realizar pesquisas em cooperação com grupos de outras instituições, disseminar conhecimentos, gerar, consolidar e modernizar bancos de dados que possibilitem armazenar as informações que possam ser a fonte de recursos para os pesquisadores das mais diversas áreas científicas.

As indagações levantadas são altamente desafiadoras e complexas, porém imprescindíveis no processo de incorporação da tecnologia e da comunicação em rede por parte de grupos de docentes, técnicos e alunos das instituições de ensino. Neste sentido, é preciso:

a) criar condições para que as IPES modernizem os métodos educacionais empregados no ensino presencial pelo uso dos meios interativos disponíveis;

b) criar condições específicas para a formação, no país e no exterior, de pessoal nas áreas envolvidas no processo, tais como: pedagogia aplicada aos meios interativos, softwares educacionais, multimídia etc;

c) fomentar o surgimento e o fortalecimento de grupos de pesquisa nas mencionadas áreas;

d) assegurar as condições de apoio à produção de material didático e o sistema logístico necessário, incentivando a disponibilização, a distância, dos conhecimentos testados presencialmente (sempre que possível);

e) possibilitar as articulações das instituições em redes interativas locais, regionais e nacionais;

f) incentivá-las para que passem a atender as demandas da sociedade mediante cursos a distância, evoluindo daí, gradativamente, para a oferta dos cursos de maior complexidade operacional (pósgraduação e graduação).

Segundo Martin RODRIGUEZ (1997) é necessário rever as dimensões educativa, tecnológica e comunicativa quanto ao papel e ao protagonismo que assumem os professores implicados na organização do trabalho pedagógico.

Todas as mudanças nos conteúdos de trabalho implicam em alterações na formação política, técnica e profissional dos trabalhadores, direcionadas à aquisição de novas competências e habilidades de pensamento abstrato, lógico e formal. Para os profissionais de educação, o grande desafio é colocar as tecnologias a serviço da produção de conhecimentos e da criação de uma nova cultura para o desenvolvimento da cidadania. 
Para que a educação a distância possa potencializar os conhecimentos, é imprescindível a presença de um novo profissional que possa atuar em EAD - o professor tutor - tema central deste estudo.

A palavra tutor traz implícita a figura jurídica outorgada pela lei, isto é, tutela e defesa de uma pessoa menor ou necessitada em sua primeira concepção. Ampliada no sistema de educação a distância, a figura do tutor passou a ser basicamente a de um orientador de aprendizagem do aluno solitário, que freqüentemente necessita do docente ou de um orientador para indicar o que mais lhe convém em cada circunstância. Pode-se admitir plenamente que o professor tutor seja nominado em outros sistemas similares como orientador acadêmico ou facilitador.

No sistema de EAD, o tutor tem um papel fundamental, pois é por intermédio dele que se garante a inter-relação personalizada e contínua do aluno no sistema e se viabiliza a articulação necessária entre os elementos do processo e a consecução dos objetivos propostos. Cada instituição que desenvolve este processo de educação busca construir seu modelo tutorial visando ao atendimento das especificidades locais regionais, incorporando nos programas e cursos, como complemento às novas tecnologias.

Os projetos de EAD devem apresentar uma base metodológica consistente e assegurar um fluxo de comunicação bidirecional mediado pela ação tutorial com acompanhamento pedagógico e avaliação sistemática da aprendizagem dos alunos.

É nesta perspectiva que se situa a ação tutorial, com o propósito de propiciar ao estudante a distância um ambiente de aprendizagem personalizado, capaz de satisfazer suas necessidades educativas.

Como mediador neste processo, o professor tutor assume papel relevante, atuando como intérprete do curso junto ao aluno, esclarecendo suas dúvidas, estimulando-o a prosseguir e ao mesmo tempo participando do processo de avaliação da aprendizagem.

\section{A organização do sistema de tutoria: concepção e características}

Uma concepção de educação só pode conviver com a anterior quando elaborar e aplicar métodos e instrumentos de trabalho suficientemente consistentes para sua transformação. 
$\mathrm{Na}$ educação superior, há pelo menos dois tipos de concepção que comandam a vida das instituições, no que se refere à sociedade brasileira: "uma é a concepção de universidade voltada ao mercado, a segunda é a concepção de universidade preocupada com a formação do cidadão, cuja racionalidade é emancipadora" (WACHOWICZ, 2000, p. 99).

As exigências necessárias diante de um mercado no qual as pessoas devem sobreviver seriam referentes às operações mentais superiores que mais parecem estar preocupadas em realmente selecionar os estudantes em vez de ensinar e fazer aprender.

A relação pedagógica presente na EAD é diversa, se fundamenta na pedagogia diferenciada, e o papel de tutor é fazer com que nasça no aluno o desejo de aprender. Sua tarefa é conforme MEIRIEU (1998) criar o enigma, ou mais exatamente fazer do saber um enigma e suscitar no aluno a vontade de desvendá-lo. As estratégias individuais de aprendizagem são elaboradas a partir do fato de que cada estudante cria seu próprio enigma.

A EAD, paradoxalmente exige uma interlocução continuada mediante o diálogo efetivo entre alunos, docentes e tutores ou orientadores acadêmicos e traz consigo a possibilidade da adoção de um novo tempo escolar, oposto à lógica do tempo da modernidade, com um maior respeito aos ritmos pessoais de cada estudante.

A orientação tutorial é compreendida assim como um dos elementos do processo educativo que propicia a ruptura da noção tempo/espaço da escola tradicional, uma vez que o processo dialógico que se estabelece entre o aluno e o tutor deve ser único e exclusivo onde o entorno, o percurso, as expectativas, as dificuldades etc. constituem elementos dinamizadores desse processo.

Esta é uma das razões que justifica a dimensão em que se situa a relação, número de alunos (de 20 até 30) por tutor orientador, a fim de que o processo de interlocução seja sustentado pelo atendimento às diferenças e pela diversidade de interesse dos estudantes.

É da responsabilidade do tutor participar do processo de acompanhamento e de avaliação da aprendizagem dos alunos. Na sede central de EAD, os professores especialistas responsáveis pelas áreas de conhecimento devem assessorar os tutores no que diz respeito ao estudo e discussão dos conteúdos e dos materiais didáticos do curso. Além disso, os professores conteudistas deverão estar à disposição dos alunos do curso em dias e horário previamente estabelecidos, via telefone e internet. 


\section{Formação do professor tutor}

Conforme R. MARIN IBÁÑEZ (1984), citado em GARCIA ARETIO (1994), é fundamental a relação pessoal entre os tutores e entre estes e as equipes da sede central. Como educador que é, além de sua formação teórica e metodológica, ao tutor são requeridas certas qualidades como maturidade emocional, capacidade de liderança, bom nível cultural, capacidade de empatia, cordialidade e habilidade para ouvir.

A educação e formação de adultos é também parte integrante do currículo de formação do professor tutor em todas as perspectivas de vida: humana, social, política, laboral, tecnológica etc. sob uma visão axiológica, ética e crítica da sociedade.

As novas tecnologias devem fazer parte integrante da formação do educador devido à necessidade de se transpor as fronteiras do educar convencional. A questão que se põe atualmente na formação do docente tutor é como utilizar as tecnologias da forma mais proveitosa e educativa possível.

\section{Características da aprendizagem de pessoas adultas}

GARCIA LLAMAS (1996), citado por MARTINS (2001), aponta alguns traços característicos da aprendizagem dos alunos:

- $\quad$ os adultos buscam experiências de aprendizagem que sejam úteis para enfrentar, com sucesso, as mudanças que ocorrem em suas vidas;

- a tensão das dificuldades da vida estimula-os às novas aprendizagens;

- $\quad$ as experiências de aprendizagem que os adultos buscam por si mesmos, relacionam-se com as mudanças que elas podem produzir em suas vidas;

- $\quad$ em geral, para os adultos, a aprendizagem não é gratificante por si mesma. Aprendem com a esperança de aplicar os conhecimentos às situações que poderão proporcionar vantagens imediatas. Isto significa que a aprendizagem para a população adulta é concebida mais como um meio do que como uma finalidade. 
Segundo José M. QUINTANA CABAÑAS (1995), quando um adulto se propõe a aprender é porque tem em vista:

- $\quad$ sua promoção social: ela será alcançada se ele adquirir certos conhecimentos específicos;

- $\quad$ adaptação profissional: para ascender em sua situação profissional;

- resolução de problemas concretos: o adulto necessita de conhecimentos pontuais para solucionar seus problemas imediatos.

\section{Perfil de competências do professor tutor}

O currículo do curso de formação de tutores não é apenas uma listagem de conteúdos ou um rol de disciplinas que contém habilidades, fatos, valores selecionados para se transmitir às gerações futuras. O currículo deve ser pensado segundo APPLE, citado por NEDER (1999) na perspectiva de sua inserção no contexto social, tendo como base os princípios da historicidade, construção e do relacional dos conhecimentos a serem produzidos pelos professores tutores e estudantes; o da diversidade e da autonomia do trabalho cooperativo; da investigação e da criticidade.

Na UFPR, os currículos dos cursos de especialização e de capacitação de tutores em EAD, para efeito didático, considera os núcleos contextual, estrutural metodológico e integrador que constituem o suporte dos módulos que compõem os currículos dos cursos. São eles: fundamentos e políticas de EAD; gestão, estrutura e funcionamento em EAD; teoria e prática tutorial em EAD, tópicos especiais em EAD, comunicação e informação em EAD e avaliação da aprendizagem.

Todos os módulos se integram às linhas de investigação do curso possibilitando uma regulamentação contínua dos processos de aprendizagem dos alunos e de avaliação do curso. 


\section{Processos de seleção, formação e avaliação dos professores tu- tores}

A discussão sobre o papel do professor tutor está posta numa visão estratégica, já que seu desempenho é o de atuar como mediador entre: o currículo, interesses e capacidades do jovem agora e, no futuro, professores, pais e alunos; alunos entre si e nos processos de ensino-aprendizagem.

O tutor precisa tornar-se ele próprio um pesquisador-em-ação. Isso requer a ampliação da idéia de pesquisa, de forma a incluir nessa visão a investigação disciplinada e reflexiva sobre a prática. Em outras palavras, sugere-se que o tutor produza conhecimento, fundamentalmente, a partir de engajamento na investigação de sua própria prática. Destaca-se, ainda, a importância de se socializar esse conhecimento.

No sentido de explicitar as implicações formativas articuladas ao papel do tutor, CASTILLO ARREDONDO (1998), selecionou os seguintes procedimentos:

- atuar como mediador;

- conhecer a realidade de seus alunos em todas as dimensões (pessoal, social, familiar, escolar);

- $\quad$ oferecer possibilidades permanentes de diálogo, saber ouvir, ser empático e manter uma atitude de cooperação;

- $\quad$ oferecer experiências de melhoria de qualidade de vida, de participação, de tomada de consciência, de elaboração dos próprios projetos de vida etc.;

- demonstrar competência individual e de equipe para analisar realidades, formular planos de ação coerentes com os resultados de análises e de avaliação, etc.;

- $\quad$ identificar suas capacidades e limitações para atuar de forma realista com visão de superação;

- manter uma atitude reflexiva e crítica sobre a teoria e a prática educativa;

- possibilitar a comunicação entre os diferentes níveis, de pessoas, de coletivos etc.

$\mathrm{Na}$ Universidade Federal de Mato Grosso a contratação dos orientadores acadêmicos (tutores) é de responsabilidade das Secretarias Estaduais e Municipais de Educação na proporção de 50\% para o Estado e 50\% para os municípios. Após a seleção, os candidatos devem participar do processo de formação que supõe a participação dos candidatos em um curso de especialização 
sobre EAD, formação de grupos de estudos para a aprendizagem de elaboração do material didático do curso e questões relacionadas ao processo de orientação em tutoria (NEDER, 1999).

\section{Desenvolvimento da ação tutorial: funções docentes, administra- tivas e de participação}

Os professores tutores são pessoas com titulação universitária de grau superior e pós-graduação, possuem experiência profissional na área de atuação e formação didático-pedagógica (ARETIO, 1996).

Não é atribuída ao professor tutor a responsabilidade docente de decidir sobre a seleção dos conteúdos das disciplinas e módulos. Sua atribuição essencial é realizar as funções de assessoramento, de mediação e avaliação no processo de aprendizagem do aluno. As intervenções do tutor, no entanto, devem ser flexíveis e possibilitar aos alunos procedimentos reflexivos e fundados em conceituações teóricas consistentes.

O tutor se encontra, portanto, diante de uma tarefa desafiadora e complexa. A formação especializada é imprescindível. Segundo SHULMAN (1995), o tutor deveria apresentar alguns conhecimentos essenciais mínimos, tais como: conhecimento dos conteúdos; conhecimento pedagógico de tipo geral com especial referência aos princípios e estratégias de manejo e organização da classe; conhecimentos sobre os contextos educacionais; conhecimentos acerca das finalidades, dos propósitos, dos valores educativos e de suas raízes históricas e filosóficas.

Funções administrativas e de participação

Além das responsabilidades pedagógicas, os professores tutores devem assumir as seguintes atividades:

- permanecer no centro associado (ou de apoio) em dias e horas fixadas no Plano Anual de Organização Docente;

- enviar informações aos professores da sede central responsáveis 
pelos módulos, sobre o nível de preparação e a receptividade dos alunos;

- promover programas para a realização de práticas, seminários, convivências e demais atividades que contribuam para a integração e formação dos alunos;

- compor as bancas nas avaliações finais presenciais e nas situações que os docentes estejam completamente impedidos de participar;

- colaborar em atividades extra-acadêmicas e de extensão cultural, quando forem solicitados.

\section{Modalidades de tutoria}

A tutoria é realizada das seguintes formas:

- à distância: o cursista, individualmente, entrará em contato com o tutor, por meio dos meios de comunicação estabelecidos, em horários definidos anteriormente. É viável também realizar contatos em pequenos grupos de estudo para formular questões ou dúvidas e solicitar ao tutor os esclarecimentos, utilizando-se de um sistema interativo de comunicação;

- presencial: o cursista, individualmente (ou em pequenos grupos), entrará em contato com o seu tutor muito mais para discutir e avaliar o processo de aprendizagem, apresentar os resultados de suas leituras, atividades e trabalhos propostos nos materiais didáticos, do que somente tirar dúvidas.

Tutoria presencial

Esta é a modalidade clássica de tutoria. Na educação a distância existem algumas divergências quanto a sua aplicabilidade. Para alguns, as seções presenciais são essenciais para o desempenho acadêmico dos alunos.

A tutoria presencial pode ser individual ou em grupo.

Tutoria grupal

Quando os problemas são similares é recomendada esta modalidade de orientação. As seções grupais têm a vantagem de proporcionar a comunicação direta entre os alunos de um curso, a troca de experiências, confronto de idéias e a busca de soluções facilitando a socialização.

A metodologia empregada nos encontros grupais é diversificada, senão 
vejamos: problematização pelos alunos, explicitação das dúvidas pelo professor-tutor, orientações sobre investigação, interlocuções com os grupos, seminários, painéis, palestras, trabalhos em equipe etc. As experiências têm demonstrado que esse tipo de tutoria fortalece o sentimento dos alunos de pertencerem a uma equipe, diminuindo a sensação de isolamento e ansiedade.

Tanto a tutoria individual como a realizada em grupos devem ser cuidadosamente planejadas, registradas em cronogramas distribuídos previamente para todos os alunos, e sua frequiência será prevista e proposta levando-se em conta as necessidades dos estudantes e a disponibilidade dos professores-tutores.

\section{Tutoria postal}

É uma modalidade econômica de comunicação que já foi bastante utilizada entre os alunos e os tutores. Atualmente os meios privilegiados são quase todos eletrônicos.

Tutoria telefônica

O telefone é um sistema de comunicação eficaz possibilitando o esclarecimento das dúvidas do aluno na mesma hora. Permite uma relação direta e interpessoal.

Para facilitar esta comunicação o tutor precisa "saber escutar", ser cordial, ter clareza de expressão e demonstrar entusiasmo, amizade e simpatia.

Tutoria por rádio

É um meio de comunicação de massa, que envolve um grande número de ouvintes. É um sistema rápido acoplado ao telefone e pode assumir o caráter bidirecional, especialmente em regiões onde o sistema de comunicação é precário.

Tutoria por multimídia

Com o avanço das tecnologias, principalmente, no campo da informática, os sistemas de comunicação estão postos diretamente na interatividade. Os procedimentos de telemática estão sendo largamente utilizados. É o caso da teleconferência, videoconferência, da videotransmissão e do correio eletrônico. A participação entre os alunos e professores é imediata, cumprindo assim uma das grandes metas da educação a distância. Merecem destaque as vantagens:

- rapidez, uma vez que as mensagens chegam ao seu destino em segun- 
dos, em qualquer parte do mundo;

- economia, pois o custo equivale a uma chamada telefônica local;

- confiabilidade, considerando que se as mensagens não chegam ao seu destinatário, por algum motivo, retornam ao emissor.

- abertura de fronteiras, as mensagens chegam ao seu destino independentemente da localização geográfica. impressas.

- arquivo de informações, as mensagens podem ser copiadas em disquete,

Grupos de discussão

São os chamados newgroups, um ponto de encontro virtual para conversar - por escrito - com pessoas que compartilham afinidades e interesses comuns. Constitui um sistema global de mensagens organizadas por áreas temáticas, proporciona um meio de intercâmbio rápido de informação variada. Pode-se compartilhar informações com grande número de pessoas em pouco tempo.

Conversação eletrônica (chat)

O chat é um modo de comunicação interativa e em tempo real, com várias pessoas, sem contudo considerar que estas se encontram no outro lado do mundo. O usuário "fala" com outro por meio de um texto que vai aparecendo na tela do computador de seu interlocutor de forma imediata.

\section{Lições aprendidas na tutoria: alguns problemas de percurso no pro- cesso de mediação}

Não existe um modelo único de tutoria. Cada instituição, dependendo de sua estrutura administrativa, pedagógica e recursos financeiros disponíveis adota formas variadas de tutoria.

Em decorrência da transição tecnológica que estamos vivenciando, alguns fatores se qualificam como primordiais e afetam a necessidade da formação dos tutores e da reciclagem dos docentes para atuar em EAD. São eles: a inovação e reconstrução dos procedimentos didáticos e metodológicos, a inserção de novas linguagens, de leituras diferentes da realidade no contexto 
da telemática etc.

Para superar os modelos unidirecionais de educação, considerando o uso das novas tecnologias, é necessária uma mudança de perspectiva e um plano superior: enfatizar o estudante como pessoa e romper com a visão de que o professor ensina e o aluno aprende.

Das prioridades com as quais nos defrontamos para a melhoria da qualidade da EAD no início deste milênio, duas parecem ser fundamentais: a investigação e a formação de professores.

Construir um projeto para Educação a Distância envolvendo o ensino, a pesquisa, a capacitação de professores e o desenvolvimento de produtos indica a necessidade de articulação de diferentes componentes, que, integrados compõem a complexidade de um sistema que contém a infra-estrutura tecnológica com a instalação de laboratórios, redes, links com a internet, acesso aos usuários, definição de ferramentas, programas e sistemas adequados às necessidades das mediações pedagógicas.

O ambiente virtual de aprendizagem é um fator de importância fundamental na construção de um projeto de EAD.

Por sua vez, a composição das equipes de trabalho deve pautar-se em critérios de excelência, a fim de promover um trabalho colaborativo e criativo, possibilitando a interatividade entre todos os elementos que compõem o universo do aluno (história de vida, família, trabalho, classe, outros grupos a que pertença etc.).

O processo de mediação, em sentido estrito, corresponde ao momento em que os alunos entram em contato com o conteúdo e as atividades, interagindo com os professores, com os colegas e técnicos no ambiente virtual de aprendizagem e por outros meios de comunicação disponíveis. Conflitos são muitas vezes inevitáveis. Constatam-se situações de múltiplo comando, ambigüidade de papéis, preocupações com as motivações dos alunos, com os procedimentos administrativos, recursos, custos, cronograma, materiais impressos e atuações diferenciadas.

Num esforço de síntese, podemos afirmar que há uma série de fatores intervenientes, que ocorrem freqüentemente, como por exemplo os hiatos de comunicação com os alunos devido problemas com o servidor. Esses hiatos provocam a sensação de abandono e solidão, desmotivando, e às vezes agravando as dificuldades já encontradas pelos estudantes.

Outro problema é o da avaliação do percurso que se revela ser insuficiente para que os estudantes possam se apropriar dos recursos disponíveis e desenvolver habilidades para utilizá-los. Essa condição tem gerado impasses 
na formação de equipes interativas.

O tutor deve estar preparado para lidar com questões relacionadas ao acúmulo de tarefas, cronogramas longos, alunos adultos que possuem idades, motivações, percepções, experiências, ritmos de trabalho e graus de formação completamente diversos.

Essa análise é muito importante, uma vez que esses diferentes perfis exigem programações diferenciadas. Nessa perspectiva, o trânsito pela diversidade deixa de ser apenas um discurso para concretizar-se em ações comprometidas com uma aprendizagem ética e diferenciada.

Enfim a capacitação é um desafio complexo pelas inúmeras razões citadas. Talvez a mais evidente seja a nossa pouca experiência em flagrar o próprio percurso, pois essa não é uma prática comumente desenvolvida entre nós, educadores.

Construir um ambiente de aprendizagem colaborativo e promover situações contínuas para o desenvolvimento da autonomia onde o aluno possa responsabilizar-se pelo seu percurso de aprendizagem, é um dos maiores desafios do docente que atua em EAD.

A reflexão contínua sobre a prática constitui um saber essencial nas palavras de Paulo FREIRE (1997) quando cita: "na formação permanente dos professores, o momento fundamental é o da reflexão crítica sobre a prática. É pensando criticamente a prática de hoje ou de ontem que se pode melhorar a próxima prática”.

\section{REFERÊNCIAS}

APARICI, R. Mitos de la educación a distancia y de las nuevas tecnologias. In: MARTIN RODRIGUEZ, E. La educación a distancia en tiempos de cambio: nuevas generaciones viejos conflitos. Madrid: De la Torre, 1999.

CARVALHO, R. Q. Novas tecnologias, trabalho e educação. In: FERRETTI, C. J. et al. (Org.). Capacitação tecnológica, revalorização do trabalho e educação. 2. ed. Petrópolis: Vozes, 1994.

CASTILLO ARREDONDO, S. Acción tutorial en los Centros Educativos: formación y práctica. Madrid: Uned, 1998.

. Evaluación del material didáctico como medio de intercomunicación enseñanza a distancia. In: ENCUENTRO IBEROAMERICANO DE EAD, 3., 1989, Costa Rica. 
Anais... Costa Rica: AISAD/ICI/UNA, 1989.

CONFERENCIA MUNDIAL SOBRE EDUCAÇÃO SUPERIOR. Declaração mundial sobre educação superior no século XXI: visão e ação, Paris, 9. out. 1998. Piracicaba: Universidade Metodista de Piracicaba - Unimep, 1998.

CONGRESSO INTERNACIONAL SOBRE TECNOLOGIA Y EDUCACIÓN A DISTANCIA, 9., 1988, San José. Anais... Costa Rica: Uned, 1998.

DEMO, P. Conhecimento moderno. Petrópolis: Vozes, 1997. . Questões para a teleducação. Petrópolis: Vozes, 1998.

FREIRE, P. Pedagogia da autonomia. São Paulo: Cortez, 1997.

GARCIA ARETIO, L. La educación a distancia hoy. Madrid: Uned, 1994. . La educación a distancia y la Uned. Madrid: Iued, 1996. . Aprender a distancia: estudiar en la Uned. Madrid: Uned, 1997.

KEEGAN, D. J. Six distance education theories. Boston, Massachussets: Hagan Cliff, 1983.

McLAREN, P. Pós-modernismo, pós-colonialismo e pedagogia. In: SILVA, T. T. Teoria crítica em tempos pós-modernos. Porto Alegre: Artes Médicas, 1993.

MARTINS, O. B. A educação superior a distância e a democratização do saber. Petrópolis: Vozes, 1991. nov. 1997.

A Unesco e a educação no mundo. Cadernos de Educação, Cuiabá, v. 0, n. 1, . Educação superior a distancia: uma modalidade de educação permanente. In: 1996.

. Educação a distância: alternativa para a construção da cidadania. Belém: UFPA,

et al. Educação a distância: um debate multidisciplinar. Curitiba: UFPR, 1999.

MEDINA, A.; DOMINGUEZ, C. Enseñanza y curriculum para la formación de personas adultas. Madrid: Pedagógicas, 1995.

MEIRIEU, P. Aprender sim, mas como? Porto Alegre: Artes Médicas, 1998.

NEDER, M. L. C. A formação do professor a distância: diversidade como base conceitual. Cuiabá, 1999. Tese (Doutorado) - Universidade Federal de Mato Grosso.

ORTEGA, J. A. La educación de adultos hoy. Granada: Fundación Educación y Futuro, 1993.

PEIXOTO, M. G. A conclusão política na pós-modernidade: a questão da democracia. São Paulo: Educ, 1998. 
SOARES, S. G. Inovações no ensino superior: reflexões sobre educação a distância. In: CASTANHO, S.; CASTANHO, M. E. L. M. (Orgs.). O que há de novo na educação superior: do projeto pedagógico à prática transformadora. Campinas: Papirus, 2000.

SHULMAN, L. Knowledge and teaching of new reforme. In: ORNESTEIN, A.; PEHAR, L. Contemporary issues curriculum. Boston: Allyson and Bacon, 1995.

QUINTANA CABAÑAS, J. M. Pedagogia social. Madrid: Dykinson, 1988.

SANTOS, B. S. Pela mão de Alice. 3. ed. São Paulo: Cortez, 1997.

UNESCO. Relatório da Comissão de Educação. 1995.

WACHOWICZ, L. A. A dialética da avaliação da aprendizagem na pedagogia diferenciada. In: CASTANHO, S.; CASTANHO, M. E. L. M. (Orgs.). O que há de novo na educação superior: do projeto pedagógico à prática transformadora. Campinas: Papirus, 2000 .

Texto recebido em 20 jan. 2003 Texto aprovado em 20 de mar. 2003 